\title{
Characteristics of a Lipolytic and Fatty Acid-requiring Butyrivibrio sp. Isolated from the Ovine Rumen
}

\author{
By GEOFFREY HAZLEWOOD AND REX M. C. DAWSON \\ Department of Biochemistry, A.R.C. Institute of Animal Physiology, Babraham, \\ Cambridge CB2 4AT
}

(Received 7 August 1978; revised 17 October 1978)

\begin{abstract}
A naturally occurring fatty acid-requiring Butyrivibrio sp. (strain S2), isolated from the ovine rumen, deacylates plant galactolipids, phospholipids and sulpholipids to obtain sufficient fatty acid for growth. Growth in vitro was promoted by adding to the growth medium a single straight-chain saturated fatty acid $\left(\mathrm{C}_{13}\right.$ to $\left.\mathrm{C}_{18}\right)$ or vaccenic acid. Palmitoleic and oleic acids also supported growth but gave lengthy lag phases probably due to their toxicity. Linolenic and linoleic acids supported good growth but they were completely hydrogenated to trans-11-octadecenoic acid which was incorporated into the bacterial complex lipids. No chain elongation, chain shortening or desaturation of the added fatty acids occurred and all were substantially incorporated into bacterial lipids of the plasmalogen type, partially as a new type of hydrophobic grouping derived from two molecules of fatty acid. The absence of fatty acid unsaturation poses the question of the maintenance of membrane fluidity within this bacterium.
\end{abstract}

\section{INTRODUCTION}

In ruminant animals, the main complex lipids ingested in the leaf-diet are the chloroplast mono- and digalactosyldiglycerides. These galactolipids are subjected to hydrolytic cleavage in the rumen (Garton, 1977) and when ${ }^{14} \mathrm{C}$-labelled grass is administered to sheep, the radioactive galactolipids disappear from the rumen contents within a matter of hours (Dawson \& Hemington, 1974; Dawson et al., 1974). Although galactolipases are present in plant leaves (Sastry \& Kates, 1964), it has been established that the ruminal lipolysis is mainly caused by the microbial population (Dawson et al., 1977).

The principal rumen bacterium (Anaerovibrio lipolytica) responsible for the hydrolysis of triglycerides does not attack galactolipids directly (Henderson, 1968) and will only liberate fatty acids when the galactose residues have been removed by prior galactosidase activity (Garton, 1977). Although Bailey (1962) reported that cell-free extracts of bovine rumen bacteria lacked galactolipase activity, some liberation of galactose occurred with the intact cells. More recently, it has been shown that rumen contents can deacylate ${ }^{14} \mathrm{C}$-labelled mono- and digalactosyldiglyceride with the formation of mono- and digalactosylglycerol, respectively (Dawson \& Hemington, 1974). Consequently, we have tried to isolate from the rumen individual organisms which can degrade galactolipids.

An anaerobic, Gram-negative, curved rod with the characteristics of the genus Butyrivibrio has been isolated from sheep rumen on a selective medium. Not only does this organism deacylate galactolipids but it is also a naturally occurring auxotroph, requiring a source of long-chain fatty acids for growth. In the absence of free long-chain fatty acids in the medium, growth of the organism is dependent on a source of esterified fatty acids such as galactolipids or phospholipids. This paper describes the isolation and identification of the 
organism, its ability to degrade complex plant lipids and the way in which it incorporates and metabolizes those fatty acids which can support its growth.

\section{METHODS}

Isolation of galactolipid-degrading bacteria. Anaerobic bacteria capable of degrading galactolipids were isolated from a selective medium (medium 1) containing mixed grass galactolipids as the main source of fermentable carbon. This medium, which was incubated under a gas phase of pure $\mathrm{CO}_{2}$, had a final $\mathrm{pH}$ of 6.8 and contained $\left(\mathrm{g} \mathrm{l}^{-1}\right): \mathrm{K}_{2} \mathrm{HPO}_{4}, 0.45 ; \mathrm{KH}_{2} \mathrm{PO}_{4}, 0.45 ;\left(\mathrm{NH}_{4}\right)_{2} \mathrm{SO}_{4}, 0.9 ; \mathrm{NaCl}, 0.9 ; \mathrm{MgSO}_{4} .7 \mathrm{H}_{2} \mathrm{O}, 0.09$; $\mathrm{CaCl}_{2}, 0.09$; $\mathrm{NaHCO}_{3}, 4 \cdot 0$; dithiothreitol, $0 \cdot 75$; resazurin, 0.001 ; mixed grass galactolipids, $0 \cdot 25$; agar, $20 \cdot 0$. Rumen fluid $(10 \%, \mathrm{v} / \mathrm{v})$, clarified by centrifugation $(20000 \mathrm{~g}, 60 \mathrm{~min})$, and distilled water were added to bring the medium to its final volume. The grass galactolipids were obtained from chloroform/methanol $(2: 1, \mathrm{v} / \mathrm{v})$ solution by evaporation in a sterile tube under a stream of sterile $\mathrm{N}_{2}$ and were dissolved in a minimum volume of methanol before being dispersed ultrasonically (KB 80/1 ultrasonic bath; Kerry's Ltd, Basildon, Essex) in sterile distilled water and added to the otherwise complete medium. A solution containing dithiothreitol and $\mathrm{NaHCO}_{3}$ was filter-sterilized before adding to the remaining components of the medium which were sterilized by autoclaving $\left(115^{\circ} \mathrm{C}, 20 \mathrm{~min}\right)$. Rumen fluid from a grazing sheep was diluted $10^{11}$ times using the above medium (minus agar and galactolipids) as diluent and samples $(0 \cdot 1 \mathrm{ml})$ of each dilution were inoculated into roll culture bottles containing $5 \mathrm{ml}$ of complete medium. Colonies were picked off after 7 and $10 \mathrm{~d}$ incubation at $39^{\circ} \mathrm{C}$ into liquid medium $(5 \mathrm{ml})$ containing, in addition to the above components, Bactocasitone $\left(5 \mathrm{~g}^{-1}\right)$ and yeast extract $\left(1.25 \mathrm{~g} \mathrm{l}^{-1}\right)$, and excluding agar. The galactose concentration in the liquid medium was determined before and after incubation, and its utilization by fermentation was taken to be indicative of catabolism of the added galactolipid. Isolate $\mathrm{S} 2$ was the most active of six colonies which were found to degrade the grass galactolipids.

Media and culture conditions. The standard medium used for routine subculture and maintenance of isolate $\mathrm{S} 2$ (medium 2) contained (g 1-1): $\mathrm{K}_{2} \mathrm{HPO}_{4}, 0.45 ; \mathrm{KH}_{2} \mathrm{PO}_{4}, 0.45 ;\left(\mathrm{NH}_{4}\right)_{2} \mathrm{SO}_{4}, 0.9 ; \mathrm{NaCl}, 0.9 ; \mathrm{MgSO}_{4}$. $7 \mathrm{H}_{2} \mathrm{O}, 0.09 ; \mathrm{CaCl}_{2}, 0.09 ; \mathrm{NaHCO}_{3}, 4 \cdot 0 ;$ cysteine. $\mathrm{HCl}, 1 \cdot 0$; resazurin, $0 \cdot 001$; Bactocasitone, $5 \cdot 0$; yeast extract, $1 \cdot 25$; galactose, $2 \cdot 5$. Clarified rumen fluid $(30 \%, v / v)$, a fatty acid preparation $(1 \%, v / v)$ and distilled water were added to bring the medium to its final volume. Sodium bicarbonate, cysteine and galactose were filter-sterilized before adding to the remaining components of the medium which were sterilized by autoclaving. The complete medium had a pH of 6.8 when equilibrated with a $100 \% \mathrm{CO}_{2}$ gas phase. The fatty acid preparation contained the non-esterified fatty acids of mixed grass galactolipids (predominantly $\alpha$-linolenic acid) dissolved in the minimum volume of methanol and dispersed ultrasonically in water for $3 \mathrm{~min}$; it was added to the medium before autoclaving to give 20 to $30 \mu \mathrm{g}$ linolenic acid ml-1.

The almost fatty acid-free (FAF) medium (medium 3) had a similar composition to medium 2 except clarified rumen fluid and the fatty acid preparation were omitted. In the course of the work described here, a number of procedures for adding individual fatty acids to the FAF medium were tested and are described fully in Results. The ultrasonic dispersal of fatty acids in a small volume of aqueous sodium taurocholate solution before adding to the bulk of the medium was the method generally used.

The preparation, distribution, inoculation and incubation of all media were carried out by the open-tube technique under an atmosphere of sterile $\mathrm{O}_{2}$-free $\mathrm{CO}_{2}$ (Hungate, 1969; Latham \& Sharpe, 1971). All cultures were incubated at $39^{\circ} \mathrm{C}$ except where specified.

Bacterial growth. Culture turbidity $\left(A_{450}\right)$ was measured with an EEL colorimeter.

Identification of isolate S2. Biochemical tests employed for identification purposes were based on those described by Holdeman \& Moore (1972). The basal liquid medium, which had a final pH of 6.8 was similar in composition to medium 3 except galactose was omitted and the cysteine concentration was only $0.5 \mathrm{~g} \mathrm{l}^{-1}$. Tween $80\left(1.0 \mathrm{~g}^{-1}\right)$ was added to satisfy the long-chain fatty acid requirement of the bacterium. Single carbohydrates $(0 \cdot 25 \%, \mathrm{w} / \mathrm{v})$ or starch $(1.5 \%, \mathrm{w} / \mathrm{v})$ were added to the medium without agar. Cellulose digestion tests were carried out according to the two procedures described by Hobson \& Mann (1971).

The production of volatile fatty acids from galactose $(0 \cdot 2 \%$, w/v) was measured as described by Hazlewood \& Dawson (1975). Other fermentation products in the same cultures were analysed by the chromatographic procedure described by Holdeman \& Moore (1972), using a Pye Unicam Series 104 chromatograph.

Rye grass galactolipids. A galactolipid concentrate containing mono- and digalactosyldiglycerides $(550 \mathrm{mg}$ galactose total) in a molar ratio of approximately $2: 1$ was prepared from fresh rye grass $(500 \mathrm{~g})$ by solvent extraction and silicic acid column chromatography using acetone as eluting solvent (Dawson \& Hemington, 1974). The non-esterified fatty acid fraction of the mixed galactolipids was obtained by refluxing a portion of the concentrate with $6 \%(\mathrm{w} / \mathrm{v}) \mathrm{KOH}$ in $95 \%(\mathrm{v} / \mathrm{v})$ aqueous ethanol for $1 \mathrm{~h}$. The free fatty acids were extracted into hexane after acidification and were subsequently shown by gas-liquid chromatography (g.l.c.) to consist mainly of $\alpha$-linolenic acid. 
Purified lipid substrates. Universally ${ }^{14} \mathrm{C}$-labelled and unlabelled mono- and digalactosyldiglycerides were prepared as described by Dawson \& Hemington (1974). An authentic sample of sulphoquinovosyldiglyceride, obtained from Dr J. L. Harwood (Department of Biochemistry, University College, Cardiff), was used to locate the ${ }^{14} \mathrm{C}$-labelled sulpholipid fraction in the total acetone-soluble lipids of rye grass.

${ }^{32} \mathrm{P}$-labelled and unlabelled phosphatidylcholine, phosphatidylethanolamine and phosphatidylinositol were prepared as described previously (Hazlewood \& Dawson, 1975). Glyceryl [ $\left.{ }^{32} \mathrm{P}\right]$ phosphorylethanolamine was formed by the alkaline deacylation of $\left.{ }^{32} \mathrm{P}\right]$ phosphatidylethanolamine (Dawson, 1976). Glycerol tri$\left[1-{ }^{14} \mathrm{C}\right]$ oleate was purchased from The Radiochemical Centre, Amersham.

Diglyceride was prepared from ovo-lecithin according to McMurray \& Dawson (1969).

Fatty acids. $1{ }^{14} \mathrm{C}$-labelled myristic, palmitic, stearic, linoleic and $\alpha$-linolenic acids were obtained from The Radiochemical Centre, Amersham. Unlabelled fatty acids were purchased from Sigma, with the exception of margaric acid (Koch-Light).

Other reagents. Sodium $\left[1-{ }^{14} \mathrm{C}\right]$ acetate was obtained from The Radiochemical Centre, Amersham. Brij 35, Tweens 20, 40, 60 and 80, sodium taurocholate and Triton X-100 were from Koch-Light. Sodium deoxycholate was purchased from Hopkin \& Williams, and sodium dodecyl sulphate from Sigma.

Preparation of lipids for incubation with isolate S2. Samples of lipid were obtained from chloroform or chloroform/methanol $(1: 1, \mathrm{v} / \mathrm{v})$ solution by evaporation, under sterile conditions where necessary, and were taken up in the minimum volume of methanol (20 to $50 \mu \mathrm{l})$ before being dispersed ultrasonically for $1 \mathrm{~min}$ in a small volume $(0.2$ to $0.5 \mathrm{ml})$ of buffer or sterile medium.

Extraction and analysis of lipids. Following incubation of isolate $\mathbf{S} 2$ with purified lipids, the reaction was stopped by adding 5 vol. chloroform/methanol $(2: 1, \mathrm{v} / \mathrm{v})$. Unchanged substrate and water-soluble breakdown products were separated in the two-phase system produced. Lipid-soluble products from the catabclism of sulpholipids, galactolipids and phospholipids were further separated and identified by thin-layer chromatography (t.l.c.) and autoradiography, using authentic compounds for reference purposes (Burns et al., 1977; Hazlewood \& Dawson, 1975). Water-soluble phosphate esters derived from ${ }^{32}$ P-labelled phospholipids were examined by paper ionophoresis and chromatography (Hazlewood \& Dawson, 1975) followed by autoradiography. Products derived from the other glycerides were analysed by t.l.c. using hexane/diethyl ether/acetic acid $\left(70: 30: 1\right.$, by vol.) or diethyl ether/petroleum ether (b.p. 40 to $60^{\circ} \mathrm{C}$ )/acetic acid $(100: 100: 2$, by vol.) as developing solvents. Non-radioactive entities were located by charring $\left[50 \%(\mathrm{v} / \mathrm{v}) \mathrm{H}_{2} \mathrm{SO}_{4} ; 110{ }^{\circ} \mathrm{C}\right]$.

${ }^{32} \mathrm{P}$-Radioactivity was determined as described previously (Hazlewood \& Dawson, 1975). ${ }^{14} \mathrm{C}$-Radioactivity was counted in a liquid scintillation counter; an external standard was utilized to measure quenching by the channels ratio technique.

Phosphorus and galactose contained in lipids were estimated by the procedures of Bartlett (1959) and Roughan \& Batt (1968), respectively.

Total lipids were extracted from bacteria as described by Clarke et al. (1976), and from cell-free culture supernatant by the method of Bligh \& Dyer (1959). Using the procedure described by Gray (1976), samples of lipids were hydrolysed in the presence of anhydrous methanolic $\mathrm{HCl}$; acyl ester groupings were converted to methyl fatty acids and aldehydogenic chains (alkenyl ethers) were converted to their dimethyl acetal derivatives. The combined ether extracts from each sample of lipid hydrolysed were analysed by (i) t.l.c. on Kieselgel $\mathrm{F}_{254}$ plates (Merck) using petroleum ether (b.p. 40 to $60^{\circ} \mathrm{C}$ )/diethyl ether/acetic acid (100:10:1, by vol.) as developing solvent and locating spots by autoradiography or spray reagents [e.g. $0 \cdot 4 \%(\mathrm{w} / \mathrm{v})$ 2,4-dinitrophenylhydrazine in $2 \mathrm{M}-\mathrm{HCl}$ ] and (ii) g.l.c. on polyethylene glycol adipate $(10 \%$, w/w, on Diatomite CAW) at 150 to $180^{\circ} \mathrm{C}$ using a Pye Unicam Series 104 gas chromatograph fitted with a flame ionization detector. Radio-g.l.c. was carried out with the same basic equipment, modified according to Kemp et al. (1975). The components of each sample were identified by reference to published data (e.g. Gray, 1976) and whenever possible by comparison with authentic standards. The procedures employed for establishing the position and geometry of the double bonds in the monoenoic acids produced from $1{ }^{14} \mathrm{C}$-labelled linoleic and linolenic acids were those described by Kemp et al. (1975).

Total lipids extracted from bacteria or cell-free culture supernatant were separated by t.l.c. using chloroform/methanol/ammonia (0.880 sp. gr.) $(110: 50: 12$, by vol.) as developing solvent. Contaminating free fatty acid, which had not been incorporated into bacterial lipids but had been extracted from the growth medium, was removed from lipid extracts by preparative t.l.c. in hexane/diethyl ether/acetic acid $(70: 30: 1$, by vol.). Free fatty acid was located by reference to markers, and the silicic acid from the remaining area of the plate was scraped into a column fitted with a sintered disc to facilitate elution of the lipids with chloroform/ methanol $(2: 1, \mathrm{v} / \mathrm{v})$ and methanol. 


\section{RESULTS}

\section{Characterization of isolate S2}

A tentative identification of isolate $\mathbf{S} 2$ was made by comparing its characteristics with those of known species as listed by Hungate (1966) and Holdeman \& Moore (1972). The organism is an obligately anaerobic, Gram-negative, curved rod and was isolated from a $10^{9}$ dilution of the rumen contents of a grazing sheep. It was motile in $18 \mathrm{~h}$ cultures, and in negatively-stained preparations examined under the electron microscope, it had a single sub-polar flagellum. Butyric and pyruvic acids were produced by fermentation of galactose and the bacterium grew vigorously in the presence of 13 out of a total of 31 different carbohydrates. Gelatin was liquefied but neither starch nor cellulose were hydrolysed. Indole was not produced and nitrate remained unchanged in the presence of the growing organism. On the basis of these characteristics, isolate $\mathrm{S} 2$ is assigned to the genus Butyrivibrio.

\section{Lipolytic activity of Butyrivibrio $\mathrm{S} 2$}

When the organism was cultured in the FAF basal medium (medium 3) supplemented with a galactolipid concentrate prepared from rye grass, t.l.c. of the total lipids extracted from the cell-free culture medium showed a rapid disappearance of both mono- and digalactosyldiglyceride, so that within $8 \mathrm{~h}$ of inoculation they had been almost eliminated (Fig. 1).

Although chromatography showed accumulation of free fatty acids, some may have been used to support growth of the auxotroph and would consequently be incorporated into bacterial lipids. In subsequent experiments, exponential phase cells from a batch culture in the FAF medium supplemented with Tween $80\left(0.6 \mathrm{~g} \mathrm{l}^{-1}\right)$ were incubated with $\left[{ }^{14} \mathrm{C}\right]$ monogalactosyldiglyceride. T.l.c. of a total lipid extract followed by autoradiography revealed a disappearance of galactolipid and a concomitant increase in ${ }^{14} \mathrm{C}$-labelled fatty acids. On this evidence, it is likely that simple deacylation is involved (Dawson \& Hemington, 1974).

Phospholipids present as impurities in the galactolipid concentrate also appeared to be decomposed by the organism (Fig. 1), and an active phospholipase was recognized in the isolate after growth on medium 2 supplemented with ${ }^{32} \mathrm{P}$-labelled phospholipids at an initial concentration of $11 \cdot 1 \mu \mathrm{g} \mathrm{P} \mathrm{ml}^{-1}$. Phosphatidylethanolamine was most rapidly attacked $(92 \%$ of radioactivity converted to water-soluble products in $24 \mathrm{~h}$ ) while phosphatidylcholine $(12 \%)$ and phosphatidylinositol $(5 \%)$ were degraded to a lesser extent. The breakdown products of phosphatidylethanolamine were identified as lysophosphatidylethanolamine, free fatty acid, glycerylphosphorylethanolamine and phosphorylethanolamine; phosphorylcholine was also identified in the water-soluble products formed from [ $\left.{ }^{32} \mathrm{P}\right]$ phosphatidylcholine. Since no phosphorylethanolamine was formed on incubation of the organism with glyceryl $\left[{ }^{32} \mathrm{P}\right]$ phosphorylethanolamine, it was concluded that phospholipases of both the $A$ and $C$ types were present. When isolate $S 2$ was cultured in medium 3 containing Tween $80\left(0 \cdot 6 \mathrm{~g}^{-1}\right)$ and galactose $\left(5 \mathrm{~g} \mathrm{l}^{-1}\right)$, phospholipases active against phosphatidylethanolamine were detected in cells at all stages of culture and in cell-free supernatants from the midexponential phase onwards. However, the activity in the culture supernatant could largely be sedimented by centrifuging $(165000 \mathrm{~g} ; 60 \mathrm{~min})$, and after concentration by ultrafiltration (PM-30 Diaflo membrane; Amicon Corp., Lexington, Mass., U.S.A.) it was excluded from Sepharose 2B indicating it to be associated with a particulate fraction of molecular weight exceeding $2 \times 10^{6}$. This suggested that the enzyme present in the supernatant was not a truly soluble enzyme but was perhaps associated with membrane fragments derived from bacteria.

The plant sulpholipid, sulphoquinovosyldiglyceride, contained in the glycolipid concentrate prepared from rye grass was also catabolized by the isolate S2 (Fig. 1). In further experiments, growth of the bacterium in medium 3 supplemented with universally ${ }^{14} \mathrm{C}$ labelled sulpholipid resulted in a rapid loss of the sulphoquinovosyldiglyceride and a 


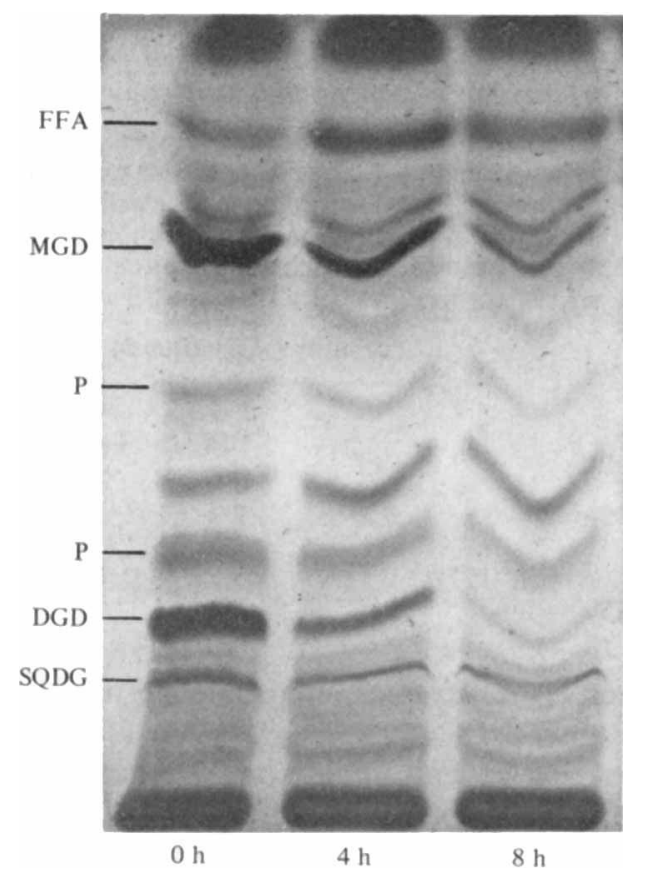

Fig. 1. T.l.c. plate showing catabolism of plant lipids by Butyrivibrio $\mathrm{S} 2$. Medium $3(10 \mathrm{ml})$ supplemented with the rye-grass galactolipid concentrate $\left(20 \mu \mathrm{g}\right.$ galactolipid galactose $\left.\mathrm{ml}^{-1}\right)$ was inoculated $(5 \%, v / v)$ with a $24 \mathrm{~h}$ culture of Butyrivibrio $\mathrm{S} 2$ grown in medium 2 . At the times shown, cultures were centrifuged $(2500 \mathrm{~g} ; 10 \mathrm{~min})$ and lipids from the supernatant fractions were extracted and chromatographed (see Methods). FFA, Free fatty acid; MGD, monogalactosyldiglyceride; P, phospholipid; DGD, digalactosyldiglyceride; SQDG, sulphoquinovosyldiglyceride.

concomitant production of ${ }^{14} \mathrm{C}$-labelled fatty acids, some of which were subsequently incorporated into bacterial lipids.

Glycerol tri $\left[1-{ }^{14} \mathrm{C}\right]$ oleate was not hydrolysed when incubated either in the presence of a growing culture of S2 or with washed exponential phase cells. Furthermore, it did not support significant growth when provided as the sole source of long-chain fatty acid in an otherwise complete medium, although over long periods of incubation $(56 \mathrm{~h})$ there was minimal incorporation $(5 \%)$ of radioactivity from glycerol tri $\left[1{ }^{14} \mathrm{C}\right]$ oleate into complex polar lipids, suggesting that very slow lipolysis may occur.

By contrast, diglyceride $\left(0 \cdot 15 \mathrm{mg} \mathrm{ml}^{-1}\right)$ added to medium 3 as the only source of longchain fatty acids supported excellent growth of isolate $\mathbf{S} 2$ and was completely catabolized. This finding explained the absence of diglyceride amongst the products derived from phosphatidylethanolamine by the phospholipase C of the isolate $\mathrm{S} 2$.

\section{Deficiency of fatty acid synthesis}

Hazlewood \& Dawson (1977) previously reported that Butyrivibrio S2 will not grow unless supplied with free long-chain fatty acids or complex lipids (e.g. galactolipids, Tween detergents) from which fatty acids can be derived by lipolysis. This requirement for longchain fatty acids was not general among Butyrivibrio species isolated from the rumen, and three other organisms isolated on different occasions and in other laboratories grew well in the almost fatty acid-free basal medium containing glucose $(0.3 \%$, w/v) as a source of fermentable carbon (Table 1). Butyrivibrio S2 did not grow in the medium plus glucose, nor when the basal medium was supplemented with a volatile fatty acid mixture (Caldwell \& Bryant, 1966) containing short-chain fatty acids including acetate, but grew vigorously in the presence of glucose and palmitic acid. On a number of occasions the organism was 
Table 1. Requirement for preformed long-chain fatty acid for the growth of Butyrivibrio species and the production of a new high molecular weight fatty acid.

Tubes containing different media were inoculated with actively growing culture. Basal medium (BM) was medium 3 from which galactose and all fatty acids had been excluded. Glucose was added at $3 \mathrm{~g} \mathrm{l}^{-1}$; volatile fatty acids (VFA) were prepared according to Caldwell \& Bryant (1966); palmitic acid $\left(C_{16: 0} ; 30 \mu \mathrm{g} \mathrm{ml}^{-1}\right)$ was dispersed with the aid of sodium taurocholate $\left(400 \mu \mathrm{g} \mathrm{ml}^{-1}\right)$. The amount of high molecular weight fatty acid produced by each strain was determined chromatographically; results are expressed as the area of the peak on the g.l.c. trace per $\mu \mathrm{g}$ lipid phosphorus.

Turbidity $\left(A_{450}\right)$ after $24 \mathrm{~h}$ incubation in:

\begin{tabular}{|c|c|c|c|c|c|c|}
\hline $\begin{array}{c}\text { Butyrivibrio } \\
\text { strain }\end{array}$ & Source & $\mathbf{B M}$ & $\begin{array}{c}\text { BM } \\
+ \text { glucose }\end{array}$ & $\begin{array}{l}\text { BM } \\
+ \text { glucose } \\
+ \text { VFA }\end{array}$ & $\begin{array}{c}\text { BM } \\
+ \text { glucose } \\
+\mathrm{C}_{16: 0}\end{array}$ & $\begin{array}{l}\text { High mol.wt } \\
\text { fatty acid }\end{array}$ \\
\hline B835 & Henderson (1973) & $0 \cdot 3$ & $2 \cdot 2$ & $2 \cdot 8$ & 0.9 & $0 \cdot 3$ \\
\hline $7 \mathrm{P} 1$ & White (1969) & $0 \cdot 4$ & $3 \cdot 0$ & $3 \cdot 2$ & $3 \cdot 4$ & $6 \cdot 0$ \\
\hline LM8/1B & Hazlewood \& Dawson (1975) & $0 \cdot 3$ & $3 \cdot 5$ & $3 \cdot 0$ & $2 \cdot 6$ & $0 \cdot 7$ \\
\hline S2 & Present isolate & $0 \cdot 3$ & $0 \cdot 2$ & $0 \cdot 2$ & $3 \cdot 1$ & $41 \cdot 5$ \\
\hline
\end{tabular}

cultured in the presence of $\left[1-{ }^{14} \mathrm{C}\right]$ acetate, but negligible incorporation of radioactivity into the lipid fraction was observed.

The relationship between growth and initial concentration of fatty acid (vaccenic acid or oleic acid) is shown in Fig. 2. The small amount of growth that occurred in the absence of an added fatty acid was due partly to the basal medium itself containing some longchain fatty acid $\left(0.26 \mu \mathrm{g}\right.$ fatty acid $\left.\mathrm{ml}^{-1}\right)$ and also to the starting inoculum $(10 \%, \mathrm{v} / \mathrm{v})$ containing some free fatty acid. The growth response was proportional to added fatty acid up to a concentration of $20 \mu \mathrm{g} \mathrm{m}^{-1}$ for both oleic and vaccenic acids.

\section{Effect of dispersing agents}

To investigate the growth response of Butyrivibrio $\mathrm{S} 2$ to various types and concentrations of fatty acid, it was necessary to disperse the fatty acids in the aqueous growth medium in a manner which did not inhibit bacterial growth. Of the detergents tried for this purpose, Tweens 20, 40, 60 and 80 all supported similar growth in the absence of other fatty acids. However, fatty acid analysis showed each Tween was heterogeneous and so, although the major fatty acid always agreed with the manufacturer's claim, they were clearly unsuitable for investigating the response to a single fatty acid.

Brij 35, Triton X-100 and sodium dodecyl sulphate all dispersed vaccenic acid (20 $\left.\mu \mathrm{g} \mathrm{ml}^{-1}\right)$ effectively but were themselves slightly inhibitory to growth at $25 \mu \mathrm{g} \mathrm{ml}^{-1}$ and caused lengthy lag phases at $40 \mu \mathrm{g} \mathrm{ml}^{-1}$. Fatty acid solutions in methanol or ethanol proved ineffective as these alcohols were inhibitory to growth at $100 \mathrm{mg} \mathrm{ml}^{-1}$ and $10 \mathrm{mg} \mathrm{ml}^{-1}$, respectively. Sodium taurocholate, by contrast, dispersed fatty acid very efficiently and, in medium 3 , vaccenic acid at $20 \mu \mathrm{g} \mathrm{ml}^{-1}$ produced maximal stimulation of growth when taurocholate was present at $500 \mu \mathrm{g} \mathrm{ml}^{-1}$; at higher concentrations taurocholate became inhibitory to growth. Taurocholate alone did not stimulate growth, and stable dispersions of all the fatty acids ( 20 to $40 \mu \mathrm{g} \mathrm{ml}^{-1}$ in the medium) could be produced by warming each acid to above its melting point, then ultrasonicating it in a small volume of aqueous solution containing taurocholate.

The organism could be grown in the presence of fatty acid complexed with clarified rumen fluid or 'defatted' bovine serum albumin, but it was difficult to prepare these entirely free of fatty acids, in order to investigate the specific effect of individual fatty acids.

\section{Growth with individual fatty acids}

Saturated straight-chain fatty acids. Myristic $\left(\mathrm{C}_{14: 0}\right)$, pentadecanoic $\left(\mathrm{C}_{15: 0}\right)$, palmitic $\left(\mathrm{C}_{16}\right)$ or margaric $\left(\mathrm{C}_{17: 0}\right)$ acids added to the FAF medium (medium 3$)$ promoted vigorous growth 


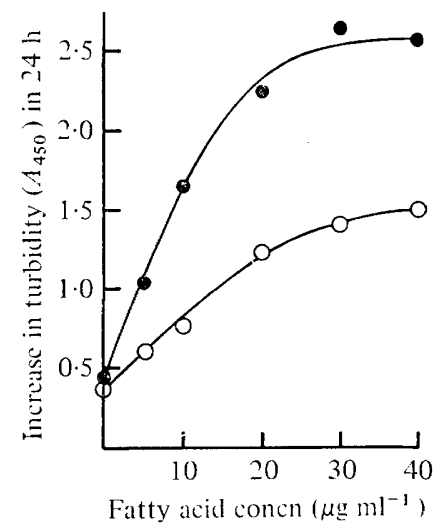

Fig. 2. Growth of Butyrivibrio S2 with fatty acids at different initial concentrations. Medium $3(10 \mathrm{ml})$ containing vaccenic acid $(O)$ or oleic acid $(O)$, dispersed with the aid of sodium taurocholate $(500 \mu \mathrm{g}$ $\left.\mathrm{ml}^{-1}\right)$, was inoculated $(10 \%, \mathrm{v} / \mathrm{v})$ with a $24 \mathrm{~h}$ culture of Butyrivibrio $\mathrm{S} 2$ and incubated for $24 \mathrm{~h}$ at $39^{\circ} \mathrm{C}$.

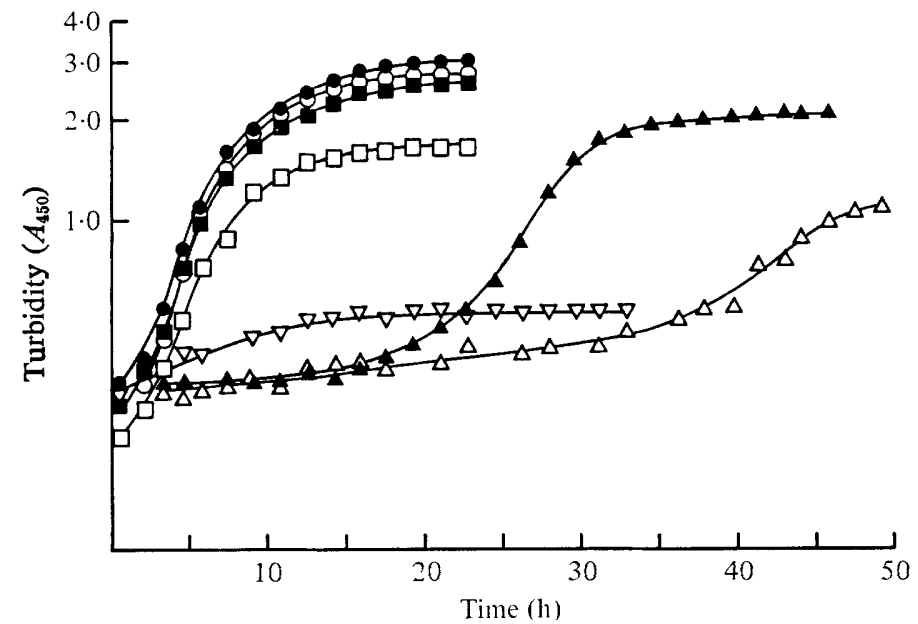

Fig. 3. Growth of Butyrivibrio S2 with different fatty acids. Medium $3(10 \mathrm{ml})$ containing no added fatty acid $(\nabla)$, vaccenic acid $(\odot)$, margaric acid $(\bigcirc)$, palmitic acid $(\mathbf{})$, myristic acid $(\square)$, palmitoleic acid $(\Delta)$ or oleic acid $(\Delta)$, each at $30 \mu \mathrm{g} \mathrm{ml}^{-1}$ and dispersed with the aid of sodium taurocholate $\left(500 \mu \mathrm{g} \mathrm{ml}^{-1}\right)$, was inoculated $(10 \%, \mathrm{v} / \mathrm{v})$ with a $24 \mathrm{~h}$ culture of Butyrivibrio S2 and incubated at $39^{\circ} \mathrm{C}$.

of Butyrivibrio S2 with little or no lag phase (Fig. 3). Growth with tridecanoic acid $\left(\mathrm{C}_{13 \pm 0}\right)$ was preceded by a lengthy lag phase, but lauric acid $\left(\mathrm{C}_{12: 0}\right)$ did not support growth. Stearic acid $\left(\mathrm{C}_{18: 0}\right)$ promoted good growth at $45^{\circ} \mathrm{C}$ but not at $39{ }^{\circ} \mathrm{C}$ unless a culture subcultured several times at $45^{\circ} \mathrm{C}$ was used to provide the inoculum.

Unsaturated fatty acids. The organism grew well with trans-11-octadecenoic acid (vaccenic acid) as the long-chain fatty acid supplement (Fig. 3) but with cis fatty acids such as palmitoleic acid $\left(\mathrm{C}_{16: 1}\right)$ and oleic acid $\left(\mathrm{C}_{18: 1}\right)$, growth only occurred after a long lag phase (Fig. 3). The lag phase with oleic acid lengthened with increasing concentration of oleic acid and, at a given concentration, it did not diminish on repeated subculture in the same medium. The organism grew well with either $\alpha$-linolenic acid $\left(\mathrm{C}_{18: 3}\right)$ or linoleic acid $\left(\mathrm{C}_{1812}\right)$ as the fatty acid growth supplement but, as indicated below, these were completely metabolized before incorporation into bacterial lipids to produce trans-11-octadecenoic acid (vaccenic acid) which was presumably therefore the activating fatty acid. 


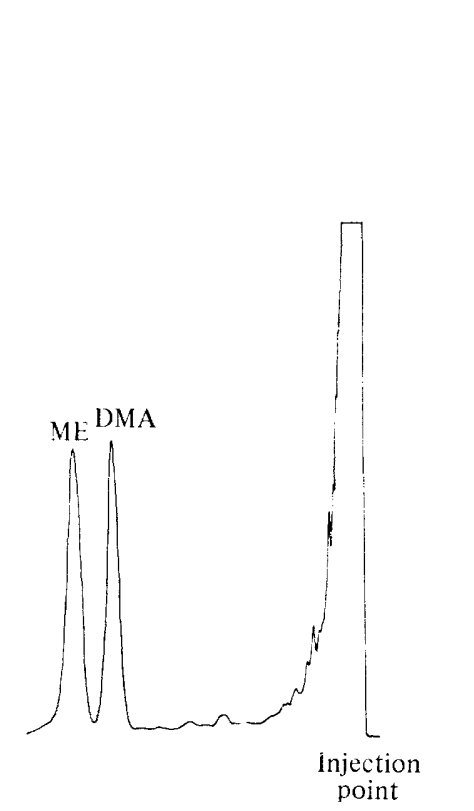

Fig. 4

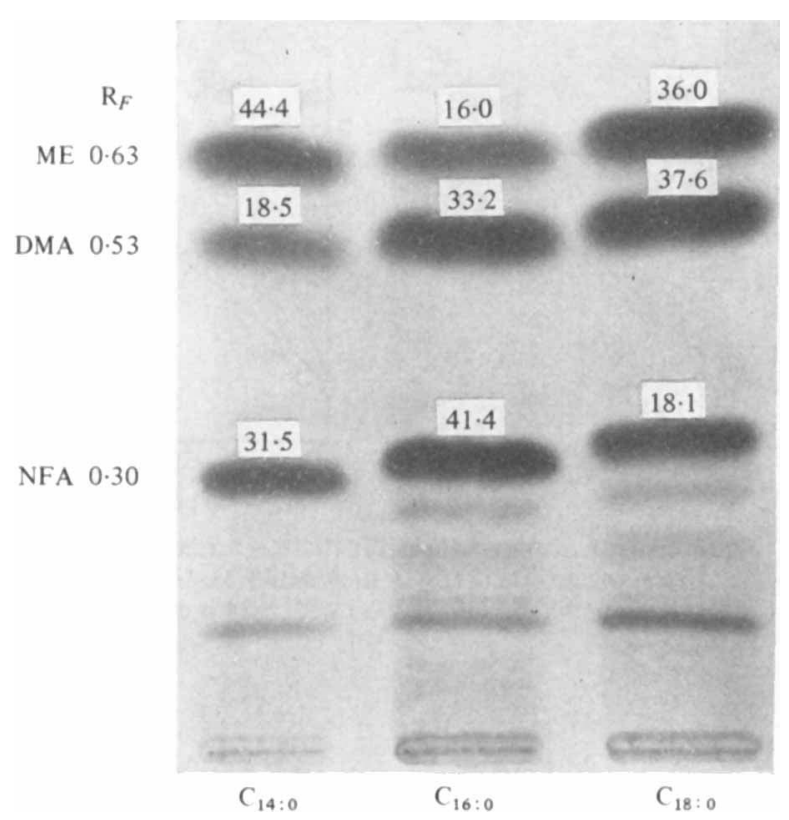

Fig. 5

Fig. 4. G.1.c. trace of the methylated hydrophobic moieties prepared from the lipids of Butyrivibrio $\mathrm{S} 2$ cultured in the presence of stearic acid $\left(\mathrm{C}_{18: 0}\right)$. Experimental conditions were as described in Fig. 6. Total cell lipids were hydrolysed with $\mathrm{HCl}(5 \%, \mathrm{w} / \mathrm{v})$ in anhydrous methanol and the ether-soluble material was subjected to g.l.c. at $170^{\circ} \mathrm{C}$ (see Methods). ME, Methyl ester; DMA, dimethyl acetal.

Fig. 5. Autoradiogram of a t.l.c. plate showing the distribution of radioactivity amongst the hydrophobic moieties of the lipids of Butyrivibrio $\mathrm{S} 2$ cultured in the presence of $1-{ }^{14} \mathrm{C}$-labelled myristic acid $\left(\mathrm{C}_{14: 0}\right)$, palmitic acid $\left(\mathrm{C}_{16: 0}\right)$ or stearic acid $\left(\mathrm{C}_{18: 0}\right)$. Experimental conditions were as described in Fig. 6. Total cell lipids from each culture were hydrolysed and the ether-soluble material was chromatographed (see Methods). Figures on the chromatogram show the percentages of the incorporated radioactivity recovered in methyl esters (ME), dimethyl acetals (DMA) and the methyl ester of the new high molecular weight fatty acid (NFA).

\section{Metabolism of fatty acids}

No evidence was obtained of any chain elongation, shortening or desaturation of any of the fatty acids examined. Following the extraction and hydrolysis of total lipids, g.l.c. of the methylated hydrophobic residues showed that, when either tridecanoic, myristic, pentadecanoic, palmitic, margaric, stearic, oleic or vaccenic acids were used as the sole source of fatty acid, each was incorporated into complex lipids of the plasmalogen type exclusively as the unchanged fatty acid (acyl ester) or the corresponding fatty aldehyde (alkenyl ether) (Fig. 4). T.l.c. of the same methylated hydrophobic residues showed that an additional component had been formed from the added fatty acid which was non-volatile under the conditions used for the g.l.c. analysis of the fatty acid methyl esters and the dimethyl acetal derivatives of the aldehydes (Fig. 5). Mass spectral analysis showed that this component had a high molecular weight and was probably formed by the combination of two fatty acid molecules. (Its identification and chemical characterization will be reported in a separate communication.) Although this third type of hydrophobic grouping was present in the highest concentration in Butyrivibrio S2, it was also observed in other Butyrivibrio species which did not require long-chain fatty acid as an essential growth factor (Table 1). Its concentration, relative to the fatty acyl and fatty aldehyde groups in the total complex lipid fraction, varied in isolate S2 according to the fatty acid supplement (Fig. 5). There was extensive incorporation of radioactivity from the $1{ }^{14} \mathrm{C}$-labelled fatty acid supplements into a wide range of complex 


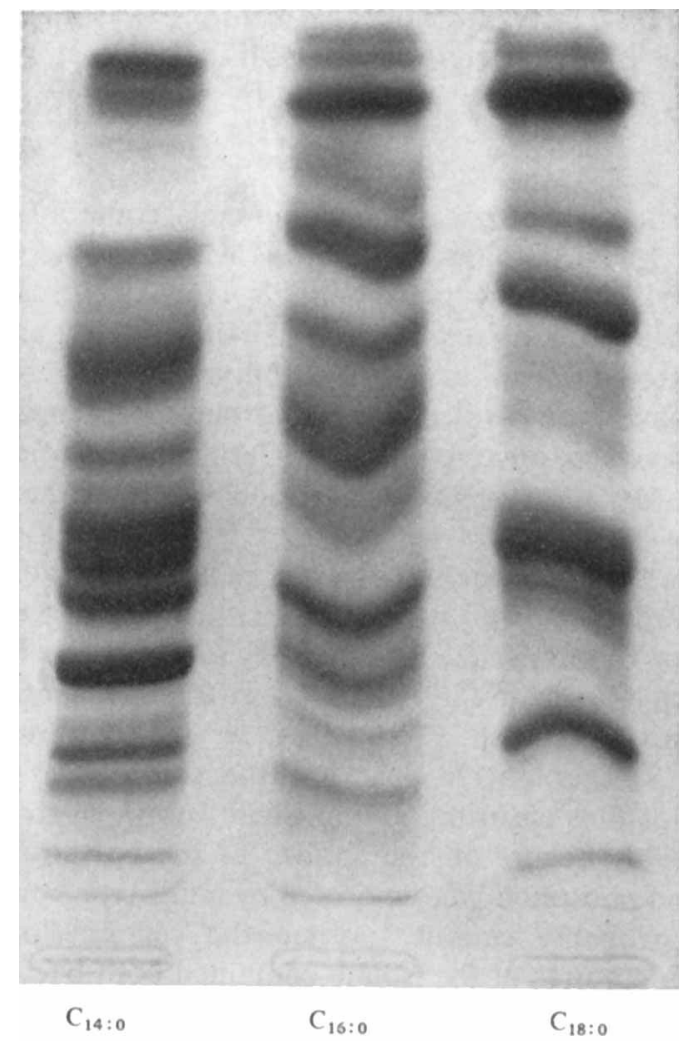

Fig. 6. Autoradiogram of a t.l.c. plate showing incorporation of radioactivity from $1-{ }^{14} \mathrm{C}-$ labelled straight-chain saturated fatty acids into lipids of Butyrivibrio S2. Medium $3(200 \mathrm{ml})$ containing ${ }^{1-{ }^{14}} \mathrm{C}$-labelled myristic acid $\left(\mathrm{C}_{14: 0}\right)$, palmitic acid $\left(\mathrm{C}_{16: 0}\right)$ or stearic acid $\left(\mathrm{C}_{18: 0}\right)$, each at $30 \mu \mathrm{g} \mathrm{ml}^{-1}$, $50 \mathrm{nCi} \mathrm{ml}^{-1}$, and dispersed with the aid of sodium taurocholate $\left(400 \mu \mathrm{g} \mathrm{ml}^{-1}\right)$, was inoculated $(5 \%, \mathrm{v} / \mathrm{v})$ with a $24 \mathrm{~h}$ culture of Butyrivibrio $\mathrm{S} 2$ which had been subcultured at least six times in medium containing only the appropriate fatty acid. After 17 to $23 \mathrm{~h}$ incubation $\left(39^{\circ} \mathrm{C}\right.$ for $\mathrm{C}_{14: 0}$ and $\mathrm{C}_{16: 0}$ cultures, $45^{\circ} \mathrm{C}$ for $\mathrm{C}_{18: 0}$ culture), early stationary phase cells were harvested by centrifugation $\left(30000 \mathrm{~g}, 15 \mathrm{~min}, 4^{\circ} \mathrm{C}\right)$ and the lipids were extracted. Total lipids were freed of contaminating free fatty acid and chromatographed (see Methods).

lipids and the synthesis of individual lipids clearly varied with the chain length of the fatty acid used to promote growth (Fig. 6).

The metabolism of $\alpha$-linolenic acid was of special interest because this acid predominates in green leaves and would be in plentiful supply to Butyrivibrio S2 in its rumen environment. The distribution of radioactivity when the organism was grown in the presence of $\left[1-{ }^{14} \mathrm{C}\right]$ linolenic acid showed substantial $(90 \%)$ incorporation into bacterial lipids. Of this, only $51 \%$ was recovered in the lipids of the whole cell fraction, the remainder being present in the cell-free supernatant fraction. The lipid of this latter fraction showed approximately the same distribution as the lipids of the whole cells and was attributed to membrane fragments split off from the cells during growth. Analysis of the whole-cell radioactivity showed $49 \%$ to be in the fatty acyl groups, $43 \%$ in fatty aldehyde groups and $6 \%$ in the high molecular weight condensation product of two fatty acid molecules. Radio-g.l.c. analysis and argentation-t.l.c. followed by oxidation and radio-g.l.c. of the resulting oxidation products indicated that the radioactivity in the acyl groupings was all present as trans-11-octadecenoic acid. Similarly, the radioactivity in the aldehydogenic groupings was associated exclusively with a $\mathrm{C}_{18: 1}$ aldehyde. Since the bacterial hydrogenation of unsaturated fatty acids uses the free acid as substrate (Kepler et al., 1970), it is likely that the original linolenic acid had 
been hydrogenated to trans-11-octadecenoic acid before it was metabolically incorporated into the complex lipids of the bacterium. $\left[1-{ }^{14} \mathrm{C}\right]$ Linoleic acid gave essentially similar results to linolenic acid.

\section{DISCUSSION}

Rumen contents, particularly of roughage-fed animals, contain large numbers of butyrivibrios (van Gylswyk, 1970; Latham et al., 1974) which participate in the digestion of cellulose, the hydrolysis of dietary phospholipids (Hazlewood \& Dawson, 1975), the hydrogenation of polyunsaturated fatty acids (Polan et al., 1964) and in the production of butyrate and the interconversion of acetate and butyrate (Latham \& Legakis, 1976; van Gylswyk, 1976). They have been divided into two groups characterized by their nutritional requirements and the products obtained from the fermentation of cellobiose (Shane et al., 1969), but little in the way of a systematic taxonomic study of the genus has been carried out.

The present organism S2 is unusual in that it has an absolute requirement for a fatty acid. This is not a general property of all rumen butyrivibrios since three other strains tested grew well in the absence of fatty acids. The inability to synthesize long-chain fatty acids is not a disadvantage since long-chain fatty acids, either free or esterified, are provided by the intake of foodstuffs into the rumen. Presumably, in vivo the powerful lipolytic enzymes present in Butyrivibrio $\mathbf{S} 2$ enable it to deacylate the chloroplast galactolipids and plant membrane phospholipids thus ensuring an immediate supply of free fatty acid for growth. Such deacylation probably occurs on the surface of the bacterium since complex lipids such as galactolipids and phospholipids, cemented by multi-type bonding in the chloroplastmembrane structure, probably cannot traverse the cell envelope. Since the cell-free supernatant from batch cultures of the isolate contained both bacterial lipids and lipolytic activity, part of the cell envelope could become detached during growth. Indeed, phospholipase $\mathrm{A}$ has been identified as a major component of the surface protein coat on the outer membrane of Acinetobacter sp. 199A (Thorne et al., 1976).

The identification of phosphorylethanolamine as a major product of phosphatidylethanolamine degradation suggests that, as well as having a system for directly deacylating this phospholipid to produce lysophosphatidylethanolamine and glycerylphosphorylethanolamine, the organism also contains a phospholipase $\mathrm{C}$. The diglyceride simultaneously produced by this phospholipase would be rapidly deacylated by lipase present in the same organism, again making free fatty acid available for growth and division. Phospholipase $\mathrm{C}$, active against the phosphoglycerides, has only a limited distribution among the bacterial genera e.g. Clostridium (Macfarlane \& Knight, 1941); Bacillus (Ottolenghi, 1965); Pseudomonas (Doi \& Nojima, 1971) and Escherichia (Proulx \& Van Deenen, 1967).

Presumably once released by lipolysis of the complex higher plant lipids, the free fatty acids are taken up by Butyrivibrio $\mathbf{S} 2$ and are used in the synthesis of bacterial lipids. The organism can use a variety of individual fatty acids although, of those tested, the straightchain saturated fatty acids from $\mathrm{C}_{14}$ to $\mathrm{C}_{17}$ and trans-11-octadecenoic acid support growth most readily. Trans unsaturated fatty acids have physicochemical properties more equivalent to the saturated fatty acids than do their cis counterparts (Chapman et al., 1966). Trans-11octadecenoic acid also supports the growth of a fatty acid-requiring mutant of Escherichia coli (Vandenhoff et al., 1975).

The long lag phase observed when cis-9-octadecenoic acid (oleic acid) or cis-9-hexadecenoic acid (palmitoleic acid) were used to promote growth is probably due to the general inhibitory effect which unsaturated fatty acids have on bacterial growth (Kodicek, 1956; Butcher et al., 1976). Henderson (1973), however, reported that the growth of the rumen bacteria Anaerovibrio lipolytica, Peptostreptococcus elsdenii, Bacteroides ruminicola and Selenomonas ruminantium was unaffected by oleic acid (up to $100 \mu \mathrm{g} \mathrm{ml}^{-1}$ ), whereas growth of a Ruminococcus sp. and production of methane by Methanobacterium ruminantium were inhibited. Growth 
of Butyrivibrio sp. B835 was stimulated by low $\left(10 \mu \mathrm{g} \mathrm{ml}^{-1}\right)$ and inhibited by high concentrations of the monoenoic acid.

$\alpha$-Linolenic acid, the major fatty acid of leaf lipids, is released in abundance in the rumen and would be potentially growth inhibitory when in the non-esterified form. The excellent growth of Butyrivibrio S2 in the presence of this fatty acid undoubtedly results from the rapid conversion of the polyunsaturated acid to trans-11-octadecenoic acid which is itself a proficient growth promoter. This ability to hydrogenate linolenic and also linoleic acid to trans-11-octadecenoic acid is common to a number of rumen bacteria including some which, like the present organism, are lipolytic (Hazlewood et al., 1976).

Apart from the hydrogenation of linolenic acid, there was no evidence for the conversion of the growth-promoting fatty acid into other fatty acids; no chain-elongating, chainshortening or desaturase activities were apparent. The incorporation of fatty acids into lipids of the plasmalogen form was not unexpected since many of the complex lipids of anaerobes including those in the rumen are plasmalogens (Kamio et al., 1969; Clarke et al., 1976). The mechanism of this conversion is at present obscure but it appears to be different from that which operates in mammalian tissues (A. K. Hajra, G. P. Hazlewood \& R. M. C. Dawson, unpublished observations).

On the other hand, the ability of the organism to condense two molecules of fatty acid to produce a high molecular weight product was unexpected. This may be somewhat analagous to the formation of simple mycolic acids by Corynebacterium diphtheriae (Gastambide-Odier \& Lederer, 1960).

Our observations that the fatty acid auxotroph can be cultured in a medium containing a single saturated fatty acid and that this fatty acid is incorporated into bacterial lipids without desaturation, raise intriguing questions concerning the physical state of the lipids within its membranes. It has been well established that to maintain the fluidity of bacterial membrane lipids, the fatty acid composition may vary in response to changes in the growth temperature, so that the proportion of unsaturated fatty acids decreases as the growth temperature rises and increases as it falls. The phenomenon has been termed homeoviscous adaptation (McElhaney, 1976; Gill \& Suisted, 1978). However, even thermophilic bacteria grown at high temperatures contain a certain minimal content of unsaturated fatty acids (McElhaney \& Souza, 1976). Cronan \& Gelmann (1973) showed that a fatty acid auxotroph of $E$. coli required at least a minimum of $20 \%$ unsaturated fatty acid in the growth supplement and it is generally agreed that fatty acid-requiring mycoplasmas (Rodwell \& Peterson, 1971), or those grown in the presence of an inhibitor of fatty acid synthesis (Silvius \& McElhaney, 1978), cannot be grown in medium containing only a straight-chain saturated fatty acid.

Perhaps the present bacterium can maintain the fluidity of its membrane lipids by introducing other hydrophobic moieties into them or by changing the nature of its complex lipids and this is being separately investigated. Certainly it shows a remarkable capacity for varying both the proportion of plasmalogen and the concentration of individual lipids in its membrane as the chain length of the unsaturated fatty acid supplied is varied from myristic through palmitic to stearic acid.

\section{REFERENCES}

BAILEY, R. W. (1962). $\alpha$-Galactosidase activity of rumen bacteria. Nature, London 195, 79-80.

Bartlett, G. R. (1959). Phosphorus assay in column chromatography. Journal of Biological Chemistry 234, 466-471.

Bligh, E. G. \& Dyer, W. J. (1959). A rapid method of total lipid extraction and purification. Canadian Journal of Biochemistry 37, 911-917.
Burns, D. D., Galliard, T. \& Harwood, J, L. (1977). Catabolism of sulphoquinovosyl diacylglycerol by an enzyme preparation from Phaseolus multiflorus. Phytochemistry 16, 651-654.

Butcher, G. W., King, G. \& Dyke, K. G. H. (1976). Sensitivity of Staphylococcus aureus to unsaturated fatty acids. Journal of General Microbiology 94, 290-296. 
Caldwell, D. R. \& BRyant, M. P. (1966). Medium without rumen fluid for non-selective enumeration and isolation of rumen bacteria. Applied Microbiology 14, 794-801.

Chapman, D., Owens, N. F. \& Walker, D. A. (1966). Monolayer studies of some synthetic 2,3-diacylDL-phosphatidylethanolamines and phosphatidylcholines containing trans double bonds. Biochimica et biophysica acta 120, 148-155.

Clarke, N. G., Hazlewood, G. P. \& Dawson, R. M. C. (1976). Novel lipids of Butyrivibrio spp. Chemistry and Physics of Lipids 17, 222-232.

Cronan, J. E. \& Gelmann, E. P. (1973). An estimate of the minimum amount of unsaturated fatty acid required for growth of Escherichia coli. Journal of Biological Chemistry 248, 1188-1195.

Dawson, R. M. C. (1976). Analysis of phosphatides and glycolipids by chromatography of their partial hydrolysis or alcoholysis products. In Lipid Chromatographic Analysis, 2nd edn, vol. 1, pp. 149-172. Edited by G. V. Marinetti. New York and Basel: Marcel Dekker.

Dawson, R. M. C. \& Hemington, N. (1974). Digestion of grass lipids and pigments in sheep rumen. British Journal of Nutrition 32, 327-340.

Dawson, R. M. C., Hemington, N., Grime, D., LANDER, D. \& KEMP, P. (1974). Lipolysis and hydrogenation of galactolipids and the accumulation of phytanic acid in the rumen. Biochemical Journal 144, 169-171.

Dawson, R. M. C., Hemington, N. \& Hazlewood, G. P. (1977). On the role of higher plant and microbial lipases in the ruminal digestion of grass lipids. British Journal of Nutrition 38, 225-232.

Dol, O. \& NoJima, S. (1971). Phospholipase C from Pseudomonas fuorescens. Biochimica et biophysica acta 248, 234-244.

Garton, G. A. (1977). Fatty acid metabolism in ruminants. In International Review of Biochemistry of Lipids II, vol. 14, pp. 337-370. Edited by T. W. Goodwin. Baltimore: University Park Press.

Gastambide-Odier, M. \& Lederer, E. (1960). Biosynthèse de l'acide corynomycolique a partir de deux molecules d'acide palmitique. Biochemische Zeitschrift 333, 285-295.

Gill, C. O. \& Suisted, J. R. (1978). The effects of temperature and growth rate on the proportion of unsaturated fatty acids in bacterial lipids. Journal of General Microbiology 104, 31-36.

Gray, G. M. (1976). Gas chromatography of the long-chain aldehydes. In Lipid Chromatographic Analysis, 2nd edn, vol. 3, pp. 897-923. Edited by G. V. Marinetti. New York and Basel: Marcel Dekker.

GylswyK, N. O. VAN (1970). The effect of supplementing a low protein hay on the cellulolytic bacteria in the rumen of sheep and on the digestibility of cellulose and hemicellulose. Journal of Agricultural Science, Cambridge 74, 169-180.

GylswyK, N. O. VAN (1976). Some aspects of the metabolism of Butyrivibrio fibrisolvens. Journal of General Microbiology 97, 105-111.

Hazlewood, G. P. \& Dawson, R. M. C. (1975). Isolation and properties of a phospholipidhydrolysing bacterium from ovine rumen fluid. Journal of General Microbiology 89, 163-174.
Hazlewood, G. P. \& Dawson, R. M. C. (1977). Galactosyl glycerides as a source of long-chain fatty acids for a naturally-occurring rumen auxotroph. Biochemical Society Transactions 5, 1721-1723.

Hazlewood, G. P., KemP, P., Lander, D. \& Dawson, R. M. C. (1976). C 18 unsaturated fatty acid hydrogenation patterns of some rumen bacteria and their ability to hydrolyse exogenous phospholipid. British Journal of Nutrition 35, 293-297.

Henderson, C. (1968). A study of the lipase of Anaerovibrio lipolytica, a rumen bacterium. Ph.D. thesis, University of Aberdeen.

Henderson, C. (1973). The effects of fatty acids on pure cultures of rumen bacteria. Journal of Agricultural Science, Cambridge 81, 107-112.

HoBson, P. N. \& MANN, S. O. (1971). Isolation of cellulolytic and lipolytic organisms from the rumen. In Isolation of Anaerobes, pp. 149-158. Edited by D. D. Shapton \& R. G. Board. London and New York: Academic Press.

Holdeman, L. V. \& Moore, W. E. C. (1972). Anaerobe Laboratory Manual, 2nd edn. Blacksburg, Virginia: Virginia Polytechnic Institute and State University.

Hungate, R. E. (1966). The rumen bacteria. In The Rumen and its Microbes, pp. 8-90. New York and London: Academic Press.

Húngate, R. E. (1969). A roll tube method for cultivation of strict anaerobes. Methods in Microbiology 3B, 117-132.

Kamio, Y., Kanegasaki, S. \& Takahashi, H. (1969). Occurrence of plasmalogens in anaerobic bacteria. Journal of General and Applied Microbiology 15, 439-451.

Kemp, P., White, R. W. \& LANDer, D. J. (1975). The hydrogenation of unsaturated fatty acids by five bacterial isolates from the sheep rumen, including a new species. Journal of General Microbiology 90, 100-114.

Kepler, C. R., Túcker, W. P. \& Tove, S. B. (1970). Biohydrogenation of unsaturated fatty acids. IV. Substrate specificity and inhibition of linoleate $\Delta^{12}$-cis, $\Delta^{11}$-trans isomerase from Butyrivibrio fibrisolvens. Journal of Biological Chemistry 245, 3612-3620.

KODICEK, E. (1956). The effect of unsaturated fatty acids of vitamin D and other sterols on Grampositive bacteria. In Biochemical Problems of Lipids, pp. 401-406. Edited by G. Popjak \& E. le Breton. London: Butterworths.

Latham, M. J. \& LegaKis, N. J. (1976). Cultural factors influencing the utilization or production of acetate by Butyrivibrio fibrisolvens. Journal of General Microbiology 94, 380-388.

Latham, M. J. \& Sharpe, M. E. (1971). The isolation of anaerobic organisms from the bovine rumen. In Isolation of Anaerobes, pp. 133-147. Edited by D. A. Shapton \& R. G. Board. London and New York: Academic Press.

Latham, M. J., Sutton, J. D. \& Sharpe, M. E. (1974). Fermentation and micro-organisms in the rumen and the content of fat in the milk of cows given low roughage rations. Journal of Dairy Science 57, 803-810. 
Macfarlane, M. G. \& Knight, B. C. J. G. (1941). The biochemistry of bacterial toxins. I. The lecithinase activity of $\mathrm{Cl}$. welchii toxins. Biochemical Journal 35, 884-902.

McElhaney, R. N. (1976). The biological significance of alterations in the fatty acid composition of microbial membrane lipids in response to changes in environmental temperature. In Extreme Environments: Mechanisms of Microbial Adaptation, pp. 255-281. Edited by M. R. Heinrich, New York, San Francisco \& London: Academic Press.

McElhaney, R. N. \& Souza, K. A. (1976). The relationship between environmental temperature, cell growth and the fluidity and physical state of the membrane lipids in Bacillus stearothermophilus. Biochimica et biophysica acta 443, 348-359.

McMurray, W. C. \& Dawson, R. M. C. (1969). Phospholipid exchange reactions within the liver cell. Biochemical Journal 112, 91-108.

Otrolenghi, A. C. (1965). Phospholipase C from Bacillus cereus: a zinc-requiring metalloenzyme. Biochimica et biophysica acta 106, 510-518.

Polan, C. E., McNeill, J. J. \& Tove, S. B. (1964). Biohydrogenation of unsaturated fatty acids by rumen bacteria. Journal of Bacteriology 88, 1056 1064.

Proulx, P. R. \& Deenen, L. L. M. Van (1967). Phospholipase activities of Escherichia coli. Biochimica et biophysica acta 114, 171-174.

Rodwell, A. W. \& Peterson, J. E. (1971). The effect of straight-chain saturated, monoenoic and branched-chain fatty acids on growth and fatty acid composition of Mycoplasma strain Y. Journal of General Microbiology 68, 173-186.

RoughaN, P. G. \& BATT, R. D. (1968). Quantitative analysis of sulpholipid (sulphoquinovosyl diglyceride) and galactolipids (monogalactosyl and digalactosyl diglycerides) in plant tissues. Analytical Biochemistry 22, 74-88.

SASTRY, P. S. \& Kates, M. (1974). Hydrolysis of monogalactosyl and digalactosyl diglycerides by specific enzymes in runner bean leaves. Biochemistry 3, 1280-1287.

Shane, B. S., Gouws, L. \& Kistner, A. (1969). Cellulolytic bacteria in the rumen of sheep conditioned to a low protein teff hay. Journal of General Microbiology 55, 445-457.

Silvius, J. R. \& McElhaney, R. N. (1978). Growth and membrane lipid properties of Acholeplasma laidlawii $\mathrm{B}$ lacking fatty acid heterogeneity. Nature, London 272, 645-647.

Thorne, K. J. I., Oliver, R. C. \& Heath, M. F. (1976). Phospholipase $A_{2}$ activity of the regularly arranged surface protein of Acinetobacter sp. 199A. Biochimica et biophysica acta 450, 335-341.

Vandenhoff, G., Gunstone, F. D., Barve, J., \& LANDS, W. E. M. (1975). Inhibition of growth of microbial mutants by trans-octadecenoates. Journal of Biological Chemistry 250, 8720-8727.

WhITE, R. W. (1969). Viable bacteria inside the rumen ciliate Entodinium caudatum. Journal of General Microbiology 56, 403-409. 